\title{
Severe wind gust thresholds for Meteoalarm derived from uniform return periods in ECA\&D
}

\author{
A. Stepek, I. L. Wijnant, G. van der Schrier, E. J. M. van den Besselaar, and A. M. G. Klein Tank \\ Climate Services Dept, KNMI, P.O. Box 201, 3730 AE De Bilt, The Netherlands \\ Correspondence to: A. Stepek (andrew.stepek@knmi.nl) \\ Received: 23 August 2011 - Revised: 14 March 2012 - Accepted: 1 May 2012 - Published: 25 June 2012
}

\begin{abstract}
In this study we present an alternative wind gust warning guideline for Meteoalarm, the severe weather warning website for Europe. There are unrealistically large differences in levels and issuing frequencies of all warning levels currently in use between neighbouring Meteoalarm countries. This study provides a guide for the Meteoalarm community to review their wind gust warning thresholds. A more uniform warning system is achieved by using one pan-European return period per warning level. The associated return values will be different throughout Europe because they depend on local climate conditions, but they will not change abruptly at country borders as is currently the case for the thresholds. As return values are a measure of the possible danger of an event and its impact on society, they form an ideal basis for a warning system. Validated wind gust measurements from the European Climate Assessment and Dataset (ECA\&D, http://www.ecad.eu) were used to calculate return values of the annual maximum wind gust. The current thresholds are compared with return values for 3 different return periods: 10 times a year return periods for yellow warnings, $2 \mathrm{yr}$ periods for orange and $5 \mathrm{yr}$ periods for red warnings. So far 10 countries provide wind gust data to ECA\&D. Due to the ECA\&D completeness requirements and the fact that some countries provided too few stations to be representative for that country, medians of the return values of annual maximum wind gust could be calculated for 6 of the 10 countries. Alternative guideline thresholds are presented for Norway, Ireland, The Netherlands, Germany, the Czech Republic and Spain and the need to distinguish between coastal, inland and mountainous regions is demonstrated. The new thresholds based on uniform return periods differ significantly from the current ones, particularly for coastal and mountainous areas.
\end{abstract}

We are aware of other, sometimes binding factors (e.g. laws) that prevent participating counties from implementing this climatology based warning system.

\section{Introduction}

There is a growing demand for accurate severe weather warnings. Worldwide the recorded number of so called "great natural catastrophes" (events with thousands of casualties, hundreds of thousands made homeless and substantial economic losses) has gradually increased over the past $60 \mathrm{yr}$ (Munich Re, 2009). Of the weather related catastrophes, $7 \%$ are caused by extratropical storms and in 2009 alone, such storms caused losses equivalent to 81 billion US Dollars. Extreme weather alarms are an important part of efforts to curb these losses. On the European scale, Meteoalarm plays a leading role in answering the demand for severe weather warnings.

Meteoalarm is an initiative by EUMETNET, the European Weather Services Network within the World Meteorological Organization (WMO), to present all weather warnings for Europe on one website: http://www.meteoalarm.eu. Since the website became fully operational in 2007, the site has become increasingly popular with more than 1 billion hits since its start and a doubling of the number of visitors since the introduction of the "Europe of regions" map. In one overview this map presents the status of all weather warnings with up-to-date reports in about 650 areas of the 30 participating countries. Warnings for as many as 10 weather parameters are provided by the National Meteorological Service (NMS) of each country, for up to $24-48 \mathrm{~h}$ ahead. The severity of the warning is related to a colour code with green for no warning and yellow, orange and red for increasing levels 
of exceptionally severe weather. Although Meteoalarm provides warning threshold guidelines for the different kinds and levels of severe weather, setting the country-specific thresholds is the responsibility of the individual NMS's. This is often an elaborate process involving various stakeholders, government officials and meteorologists. The major drawback of the exclusive national focus in this process and the noncompulsory nature of the Meteoalarm guidelines is that it leads to questionable differences in the frequency and level of warnings between neighbouring countries.

Meteoalarm became aware of this problem and instigated this study of a warning system that both reflects the specific national needs while maintaining a pan-European uniform issuing frequency for severe weather. The need for increased uniformity is illustrated in Fig. 1, which shows the Meteoalarm wind gust warnings issued in the period from 1 August 2007 to 30 June 2009. This figure shows issuing frequencies ranging from as much as $62 \%$ to as few as $0.15 \%$ for all warnings combined (yellow, orange and red). For the orange warning level, the issuing frequency varies between $15.3 \%$ and $0 \%$.

The aim of this study is to develop alternative Meteoalarm guidelines for the thresholds of wind gust warnings. These alternative guidelines are based on one return period per warning level for the whole of Europe thus providing a panEuropean uniform warning system. Thresholds based on the associated return values are representative of the local wind climate and consequently give a good indication of the possible danger of the event and its impact on society.

The return periods that are used to represent the warning levels are loosely based on the current Meteoalarm guidelines for median sized countries and therefore include past damage experience of the NMS's as explained in Sect. 3.1. In this study we will derive return values associated with these return periods for station data from 6 European countries regionalised into coastal, inland and mountain areas. In doing so we derived warning thresholds that depend on local wind climate conditions that not only vary between countries, but are also determined by the topographical properties of the area. Finally, the new wind climatology based thresholds are compared to the existing ones.

\section{Data}

\subsection{European Climate Assessment and Dataset (ECA\&D)}

This study uses the framework and data of the European Climate Assessment and Dataset (ECA\&D, http://www.ecad. eu, Klok and Klein Tank, 2008; Klein Tank et al., 2002). ECA\&D was initiated in 1998 by the European Climate Support Network. Both ECA\&D and Meteoalarm are EUMETNET initiatives.
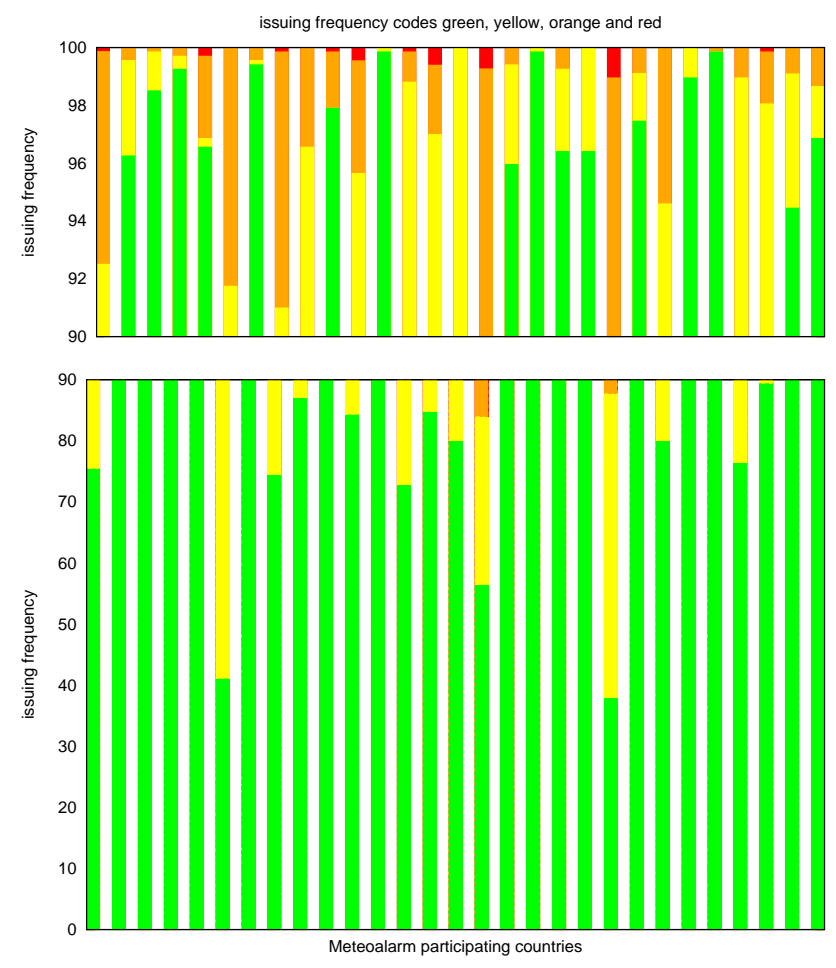

Fig. 1. Histogram of the issuing frequency of wind gust warnings for the participating Meteoalarm countries, based on 666 days between 1 August 2007 and 30 June 2009. The colours in the diagram correspond to the colour coding of the warning (yellow, orange and red are increasing levels of warning and green means no warning). Source: Meteoalarm, EMMA EUMETNET.

ECA\&D currently (January 2012) receives data from 62 countries throughout Europe and the Mediterranean, contains daily data from more than 4800 stations and serves as a data portal and climate monitoring tool for the climate research community. New stations are regularly added to the database.

Validated daily wind data (average wind speed, wind direction and maximum wind gust) were added to the ECA\&D dataset in the run-up to this study. So far 12 countries provide wind data: the Czech Republic, Estonia, Germany, Hungary, Ireland, Latvia, Luxembourg, The Netherlands, Norway, Slovenia, Slovakia and Spain. However, Slovenia and Slovakia do not provide wind gust data. Figure 2 shows a map of the stations providing daily maximum wind gust data.

Table 1 shows (in the second column) the number of these stations per country at the time of writing (January 2012). The data are validated by quality control algorithms (see Appendix A) and the number of stations which meet the completeness requirement of having at least 350 days per year with valid data, for more than $80 \%$ ( $>16 \mathrm{yr}$ ) of the years in the 1991-2010 period, are shown in the third column. These are the stations for which a Gumbel distribution is fitted. 


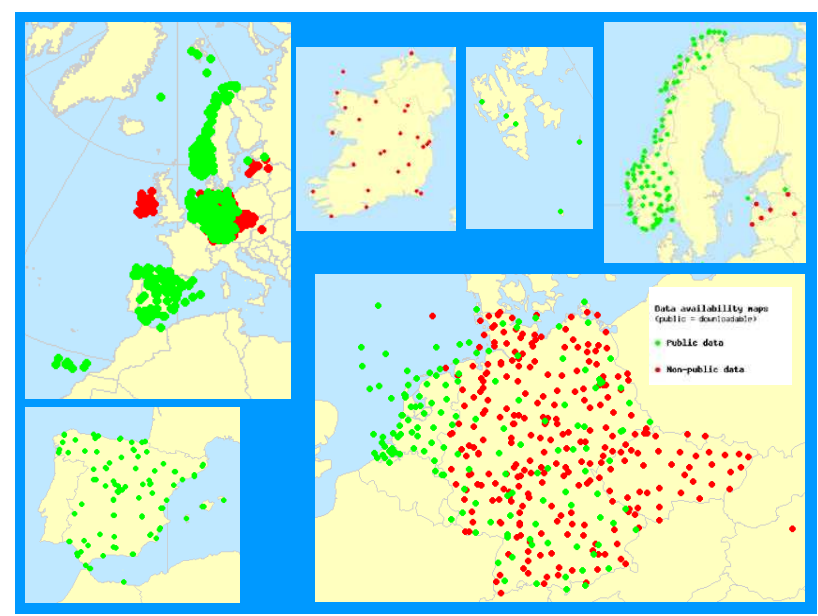

Fig. 2. Maps of all the stations with wind gust data in ECA\&D (January 2012). "Red" stations denote stations for which daily maximum wind gust data is not downloadable via the ECA\&D webpages; for "green" stations daily maximum wind gust is available. Maps are available via: http://www.ecad.eu/utils/mapserver/ stations.php.

The last column of Table 1 shows the number of stations for which this fit fails to meet the Anderson-Darling test, which is a test to validate the validity of the fit (see Sect. 3.1).

Table 2 describes how each element is aggregated to the daily level by the respective NMSs. There is a lack of uniformity in aggregation procedures to the daily level which is particularly pronounced for daily average wind speed. For daily maximum wind gust, the length of the sample varies between countries (although most have either a 2 or a 3-s interval) and the interval over which a maximum wind gust is recorded is not uniform.

\subsection{Construction of continuous series}

Time series which have gaps are made continuous with a procedure referred to as blending. With the blending procedure, the gaps are filled with data from nearby stations that are at most $12.5 \mathrm{~km}$ away and differ no more than $25 \mathrm{~m}$ in elevation. If there are no ECA\&D stations nearby, data from the Global Telecommunication System (GTS World Meteorological Organization, 2007) are used. GTS data is also used to update the series to the most recently available date until validated data from the NMSs become available. The GTS data are used in operational weather forecasting where information has to be processed in near real time so the data are non-validated, of relatively poor quality and relatively often missing (Klok and Klein Tank, 2008; Klein Tank et al., 2002; van den Besselaar et al., 2012). The analysis in this paper is based on blended series.
Table 1. Information of the number of stations per country which participate in this study. The number of stations per country with wind gust data in ECA\&D is shown in the second column. The third column gives the number of stations that meet the completeness requirement of having at least 350 days of valid data per year and for which an annual maximum wind gust was calculated for more than $80 \%$ of the years in the 1991-2010 period. For these stations, a Gumbel fit was calculated. The fourth column shows the number of stations for which the Gumbel distribution fit failed to pass the Anderson-Darling test.

\begin{tabular}{lrrr}
\hline Country & $\begin{array}{r}\text { no. } \\
\text { stations } \\
\text { provided }\end{array}$ & $\begin{array}{r}\text { no. stations for } \\
\text { which a Gumbel } \\
\text { was calculated }\end{array}$ & $\begin{array}{r}\text { no. stations } \\
\text { failing to meet } \\
\text { meet }\end{array}$ \\
\hline Czech Republic & 37 & 15 & 2 \\
Estonia & 2 & 2 & 0 \\
Germany & 317 & 136 & 14 \\
Hungary & 1 & 0 & 0 \\
Ireland & 25 & 11 & 1 \\
Latvia & 6 & 5 & 4 \\
Luxembourg & 1 & 0 & 0 \\
The Netherlands & 60 & 32 & 4 \\
Norway & 100 & 17 & 6 \\
Spain & 107 & 75 & 17 \\
\hline
\end{tabular}

\section{Methods}

\subsection{Choosing return periods and calculating return values}

The choice of return periods was based on the current Meteoalarm guidelines for a median sized country. The guidelines for all the Meteoalarm countries and those for a median sized country are shown in Table 3 . Although there are problems with the existing guidelines, they are loosely based upon the warning issuing frequencies of the participating NMSs. The NMSs base their choice of warning thresholds on past experience of the damage caused by severe weather and this experience needs to be reflected in the choice of the return periods.

For a median sized country yellow and red warnings are, according to the current guidelines, issued respectively more than 8-9 times a year and less than once in 3-4 yr (Table 3). Consequently, the proposed return periods used here are: 10 times per year for yellow, $2 \mathrm{yr}$ for orange and $5 \mathrm{yr}$ for red. Values related to a median sized country are chosen because, as Table 3 shows, the guideline is unrealistic for very small and very large countries. By choosing the median, we expect to extract the valuable experience of past dangerous weather events from the guidelines while avoiding the problem exhibited by small and large country sizes.

Return values are calculated for time series of the annual maximum wind gust. The motivation behind the choice of annual maximum wind gust, rather than seasonal maxima, was that most current warning thresholds are valid all year. Despite this, weather forecasters do account for seasonality 
Table 2. Country, the method of aggregating $f g, f x$ and $d d$ and the number of stations with wind gust data available in ECA\&D (January 2010).

\begin{tabular}{|c|c|c|c|}
\hline Country & Average windspeed $f g\left(\mathrm{~m} \mathrm{~s}^{-1}\right)$ & Max gust $f x\left(\mathrm{~m} \mathrm{~s}^{-1}\right)$ & Direction $d d\left(^{\circ}\right)$ \\
\hline Czech Republic & $\begin{array}{l}\text { Average wind speed, mean of 07:00, 14:00 and } \\
\text { 21:00 CET }\end{array}$ & Max. $3 \mathrm{~s}$ gust from 0:00-00:00 UTC & - \\
\hline Estonia & $\begin{array}{l}\text { Mean of } 8 \times 10 \text { min average speeds at } \\
21: 00 \text { UTC } \\
\text { previous day and 00:00, 03:00, 06:00,09:00, } \\
12: 00,15: 00,18: 00 \text { UTC today }\end{array}$ & Max gust from 18:00-18:00 UTC & - \\
\hline Germany & $24 \times 6 \times 10$ min averages & Max $3 \mathrm{~s}$ gust from 00:00-00:00 UTC & Speed weighted vectorial average \\
\hline Hungary & $24 \times 10 \mathrm{~min}$ averages & Max $2 \mathrm{~s}$ gust from 00:00-00:00 UTC & $\begin{array}{l}\text { Unit vectorial average } 10 \text { min wind } \\
\text { dir from 00:00-00:00 UTC }\end{array}$ \\
\hline Ireland & $24 \times 10 \mathrm{~min}$ or $24 \times 6 \times 10 \mathrm{~min}$ averages & Max $3 \mathrm{~s}$ gust from 00:00-00:00 UTC & at $12: 00 \mathrm{UTC}$ \\
\hline Latvia & $\begin{array}{l}\text { Average } 10-\text { min wind speed from } 23: 00 \mathrm{UT} \\
\text { previous day-22:00 UT today ( } 24 \text { values) }\end{array}$ & $\begin{array}{l}\text { Average wind gust from 23:00 UT pre- } \\
\text { vious day-22:00 UT today ( } 24 \text { values) }\end{array}$ & $\begin{array}{l}\text { Unit vectorial average } 2 \text {-min wind } \\
\text { direction from 23:00 UT previous } \\
\text { day-22:00 UT today ( } 24 \text { values) }\end{array}$ \\
\hline Luxembourg & - & Max $2 \mathrm{~s}$ gust from 00:00-00:00 UTC & Direction at max gust time \\
\hline $\begin{array}{l}\text { The } \\
\text { Netherlands }\end{array}$ & $24 \times 10$ min averages & Max $3 \mathrm{~s}$ gust from 00:00-00:00 UTC & $\begin{array}{l}\text { Unit vectorial average of } 06: 00 \text {, } \\
12: 00 \text { and } 18: 00 \text { UTC }\end{array}$ \\
\hline Norway & Average of 06:00, 12:00, 18:00 UTC & Max 10 s gust from 18:00-18:00 UTC & at $12: 00 \mathrm{UTC}$ \\
\hline Slovenia & $\begin{array}{l}\text { Mean of } 3 \times 10 \mathrm{~min} \text { average speeds at } 06: 00 \text {, } \\
\text { 13:00 and 20:00 UTC }\end{array}$ & - & - \\
\hline Slovakia & Average of $06: 00,12: 00,18: 00$ UTC & - & - \\
\hline Spain & $\begin{array}{l}4 \times 10 \mathrm{~min} \text { averages at } 00: 00,07: 00,13: 00 \text {, } \\
18: 00 \text { UTC }\end{array}$ & Max $3 \mathrm{~s}$ gust from 00:00-00:00 UTC & $\begin{array}{l}\text { Unit vectorial average of } 00: 00 \text {, } \\
07: 00,13: 00,18: 00 \text { UTC }\end{array}$ \\
\hline
\end{tabular}

(even if the formal warning threshold does not). For wind gust this is related to, e.g. the fact that foliated trees in summer suffer damage at lower wind gust speeds than bare trees in winter.

To establish the 2 and 5 yr return values, a Gumbel distribution is fitted to the annual maxima from the period 19912010 and an Anderson-Darling test (Stephens, 1986) with a $5 \%$ significance level is used to determine the quality of the fit. Gumbel is preferred over the alternative GEV distribution which may give a better fit, but which generates return values that are much more unstable (Hogg and Swail, 2002). The Weibull distribution, which is often used as a fit for wind speed measurements, does not work well for extremes (Perrin et al., 2006). This a priori choice for a Gumbel distribution was checked by performing a GEV fit and testing if the shape parameter was close enough to zero. $82 \%$ of the Gumbel fitted Norwegian stations passed the test. This supports the choice for Gumbel over the two other forms of the GEV. Table 1 gives in the last column the number of stations for each country for which no adequate Gumbel fit could be found (and are excluded from further analysis).

The return values associated with the code yellow threshold (10 times per year) are calculated using daily maximum wind gusts from the 1991-2010 period for each station. These values are ranked and the value which occurs on average 10 times per year is selected.

\subsection{Breakdown by topographical area}

Return values of annual maximum wind gusts based on uniform return periods show a distinct ordering. This ordering reflects the local topography. A natural grouping of coastal, inland and mountain stations is evident from Figs. 3 and 4, which show the different wind climates of these groups. In Fig. 3, the $2 \mathrm{yr}$ and $5 \mathrm{yr}$ return values for the period 19912010 are set out against the distance between the station and the coastline where the open sea begins. Figure 3 shows that the gusts decrease rapidly with distance as the greater surface roughness of the land slows the wind down. For both 2 and $5 \mathrm{yr}$ return values, the influence of the sea is no longer "felt" more than about $50 \mathrm{~km}$ away from the coast and these stations are defined as inland stations in this study. Eight obvious outliers with unrealistically high return values were identified and left out of the analyses: German inland stations Weinbiet, Neubrandenburg, Buckeburg and Berlin-Alexanderplatz and Czech inland stations Luka, Kocelovice and Pribyslav (see Appendix B). These stations are not shown in Fig. 3.

On the basis of the data pictured in Fig. 3, a provisional criterion for coastal stations is that these stations should be less than $\approx 12 \mathrm{~km}$ from the coastline. Coastal stations include stations with the prevailing wind from the sea, sometimes in very flat areas (The Netherlands), sometimes in areas where the coast is steep and complex (parts of the Spanish coastline 
Table 3. Meteoalarm return period guidelines are proportional to the size of the country with higher frequencies for larger countries. The prescribed frequency of issuing orange warnings lies between those for the red and yellow warnings.

\begin{tabular}{|c|c|c|c|}
\hline $\begin{array}{l}\text { Country } \\
\text { Name }\end{array}$ & $\begin{array}{r}\text { Country } \\
\text { Size }\left(\mathrm{km}^{2}\right)\end{array}$ & $\begin{array}{l}\text { Red warnings should } \\
\text { be issued less than... }\end{array}$ & $\begin{array}{l}\text { Yellow warnings should } \\
\text { be issued more than ... }\end{array}$ \\
\hline Standard size & 300000 & once a year & 30 times a year \\
\hline Austria & 83858 & once in $3-4 \mathrm{yr}$ & 8-9 times a year \\
\hline Belgium & 30528 & once in $9-10 \mathrm{yr}$ & 3-4 times a year \\
\hline Cyprus & 9251 & once in $32-33 \mathrm{yr}$ & about once a year \\
\hline Czech Republic & 78866 & once in $3-4 \mathrm{yr}$ & 7-8 times a year \\
\hline Denmark & 43094 & once in $6-7 \mathrm{yr}$ & 4-5 times a year \\
\hline Estonia & 45100 & once in $6-7 \mathrm{yr}$ & 4-5 times a year \\
\hline Finland & 338145 & 1-2 times a year & 33-34 times a year \\
\hline France & 643427 & about 2 times a year & $64-65$ times a year \\
\hline Germany & 357022 & 1-2 times a year & $35-36$ times a year \\
\hline Greece & 131957 & once in $2-3 \mathrm{yr}$ & 13-14 times a year \\
\hline Hungary & 93032 & once in $3-4 \mathrm{yr}$ & 9-10 times a year \\
\hline Iceland & 103000 & once in $2-3 \mathrm{yr}$ & 10-11 times a year \\
\hline Ireland & 70273 & once in $4-5$ years & 7-8 times a year \\
\hline Italy & 301318 & about once a year & 30-31 times a year \\
\hline Latvia & 64600 & once in $4-5 \mathrm{yr}$ & 6-7 times a year \\
\hline Lithuania & 65300 & once in $4-5 \mathrm{yr}$ & 6-7 times a year \\
\hline Luxembourg & 2586 & once in $116-117 \mathrm{yr}$ & about once in $4 \mathrm{yr}$ \\
\hline Malta & 316 & once in $949-950 \mathrm{yr}$ & about once in $33 \mathrm{yr}$ \\
\hline The Netherlands & 41528 & once in $7-8 \mathrm{yr}$ & 4-5 times a year \\
\hline Norway & 385155 & 1-2 times a year & 38-39 times a year \\
\hline Poland & 312685 & about once a year & $31-32$ times a year \\
\hline Portugal & 91982 & once in $3-4$ years & 9-10 times a year \\
\hline Romania & 238391 & about once a year & 23-24 times a year \\
\hline Serbia & 77474 & once in $3-4 \mathrm{yr}$ & $7-8$ times a year \\
\hline Slovakia & 49033 & once in $6-7 \mathrm{yr}$ & 4-5 times a year \\
\hline Slovenia & 20256 & once in $14-15 \mathrm{yr}$ & 2-3 times a year \\
\hline Spain & 505992 & about 2 times a year & 50-51 times a year \\
\hline Sweden & 449964 & 1-2 times a year & 44-45 times a year \\
\hline Swiss & 41284 & once in $7-8 \mathrm{yr}$ & 4-5 times a year \\
\hline UK & 242900 & about once a year & 24-25 times a year \\
\hline Median & 81362 & once in $3-4 \mathrm{yr}$ & 8-9 times a year \\
\hline
\end{tabular}

and Canary islands). But there are also coastal stations with prevailing winds from the land (east coast of Spain). Furthermore, the station elevation from the coastal stations varies from sea level to as high as $632 \mathrm{~m}$ (Tenerife/Los Rodeos). That is why a large spread in return values is found for coastal areas (Fig. 3).

The definition of coastline used, is that all points on this coastline are the centre of a circle of radius $20 \mathrm{~km}$, with no land within the semicircle on the sea side. The flat side of this semicircle must touch land and be oriented in such a way that no other such semicircle would have its centre closer to land. In this way the wind on the sea side of this coastline is undisturbed by the slowing effect of land because the wind in most circumstances recovers its strength $20 \mathrm{~km}$ downwind from land (Barthelmie and Pryor, 2004). This definition of coastline was used instead of simply the distance to the nearest coast so that stations at the inland edge of long estuaries with an inland wind climate would not be incorrectly sorted into the group of coastal stations. This method of calculating the distance to the coastline is consistently applied for all stations which means that stations such as Palma de Mallorca, Ibiza, Almeria and Tarifa (Spain), Cuxhaven, and Emden (Germany) and Stavoren (The Netherlands) are sorted into the intermittent station category, whereas the actual distance to open water is very small (e.g. Tarifa is less than $1 \mathrm{~km}$ away from the Strait of Gibraltar, but no $20 \mathrm{~km}$ semicircle fits in this $16 \mathrm{~km}$ narrow channel).

All the 2 yr return values (with the exception of mountain station Avila) were plotted as a function of station elevation in Fig. 4 which shows the following:

- Coastal stations (red plusses, distance to open sea $\lesssim 12 \mathrm{~km}$ ) which have a relatively large spread in gust values. 


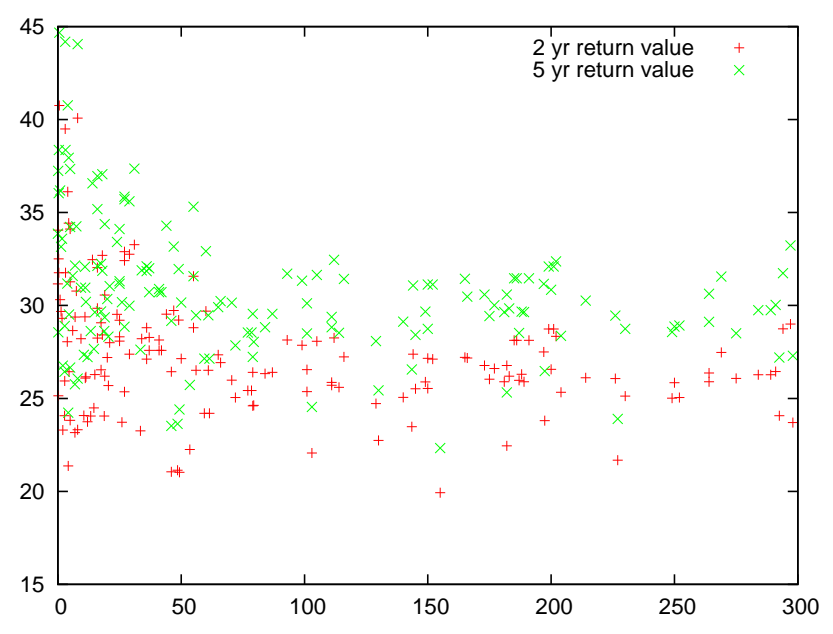

Fig. 3. Two and five year return values of annual maximum wind gust $\left(\mathrm{m} \mathrm{s}^{-1}\right)$ for the period 1991-2010 against distance $(\mathrm{km})$ between station and the coastline where the open sea begins.

- Intermediate stations (green crosses, distance to open sea is $>12 \mathrm{~km}$ or $\leq 50 \mathrm{~km}$ ) which are not analyzed.

- Inland stations (blue stars, distance to open sea $\gtrsim 50 \mathrm{~km}$ ) where the spread in return values is smaller.

- Mountain stations (pink squares, heights $\gtrsim 700 \mathrm{~m}$ ) where the $2 \mathrm{yr}$ return value increases with elevation. There are 48 stations higher than $700 \mathrm{~m}: 20$ in Spain (excl. Avila), 16 in Germany, 7 in The Czech Republic and 1 in Norway. Figure 4 clearly shows steeply increasing return values for stations higher than $700 \mathrm{~m}$.

There are a number of stations with an elevation exceeding $700 \mathrm{~m}$ where relatively low return values are measured (see Appendix B), but this is mainly because they are in valleys surrounded by high mountains, in or very near forests and/or in built-on areas. Most stations support the provisional choice for $700 \mathrm{~m}$ as the lower limit of the elevation criterion for mountain stations. Note that station Zugspitze in Germany at $2964 \mathrm{~m}$ is not included in the plot to make it clearer (it has a $2 \mathrm{yr}$ return value of $48.8 \mathrm{~m} \mathrm{~s}^{-1}$ ).

The increase in the wind above $700 \mathrm{~m}$ may be due to the presence of higher winds above the planetary boundary layer (PBL). Liu and Liang (2010) showed that for land stations, the daily average of the PBL height is about $600 \mathrm{~m}$.

In future work, the criteria to distinguish coastal, inland and mountainous stations may be improved using a denser and more homogeneous network of stations in more countries.

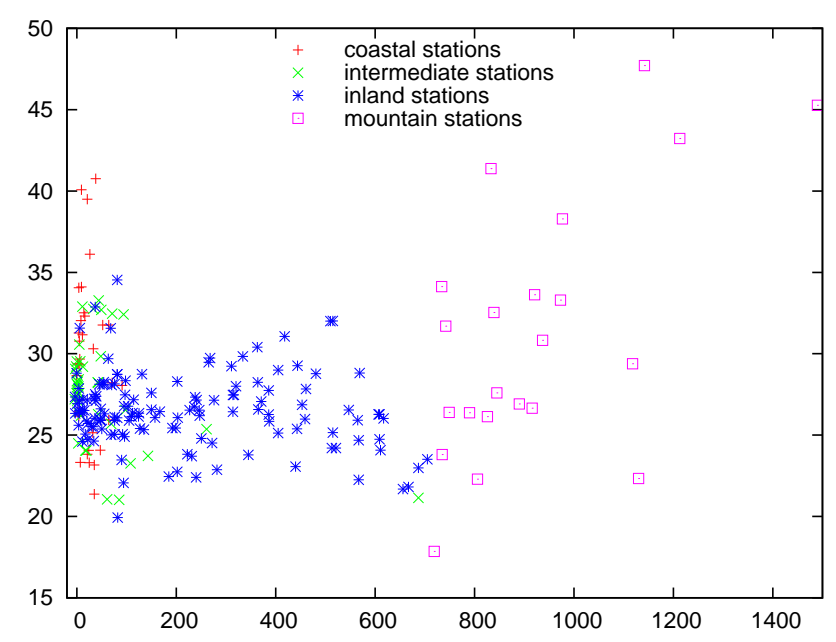

Fig. 4. Two year return values $\left(\mathrm{m} \mathrm{s}^{-1}\right)$ for the period 1991-2010 as a function of station height $(\mathrm{m})$ : red plusses are coastal stations, green crosses are intermediate stations, blue stars are inland stations and pink squares are mountain stations.

\section{Results}

\subsection{Spatial variation of the return value results}

Figure 5 shows the 10-times a year, once in $2 \mathrm{yr}$ and once in $5 \mathrm{yr}$ return values for the stations in Europe based on the 1991-2010 period. This figure clearly shows the higher return values associated with the coastal stations. The maxima in return values seen inland are related to mountain stations.

The median of the return values for each topographical area of each country is presented in Table 4 . The number of stations on which the median is based is shown in brackets. Table 4 shows, as expected, that the wind climate is more extreme in coastal and mountainous areas than in inland areas. In Norway and Ireland the difference between inland and coastal stations increases with increasing return period (Table 4). This is not the case for Germany, The Netherlands and Spain where the difference is significantly smaller than for the other countries. The difference in return values is especially small for The Netherlands and Spain, which is probably due to the relatively low surface roughness of The Netherlands and the fact that most of the Spanish coast is sheltered by land for the prevailing wind direction. Only four of the 18 Spanish coastal stations are less than $12 \mathrm{~km}$ to the northeast of open water: Cadiz and Rota Nas (both on the south coast of Spain, west of the Strait of Gibraltar) and the island stations Tenerife and Menorca. In the case of Spain, a relatively high average elevation compared to the coastal stations of the other countries also plays a role ( $82 \mathrm{~m}$ compared to values ranging from $2.3 \mathrm{~m}$ for The Netherlands to $17.8 \mathrm{~m}$ for Norway). 


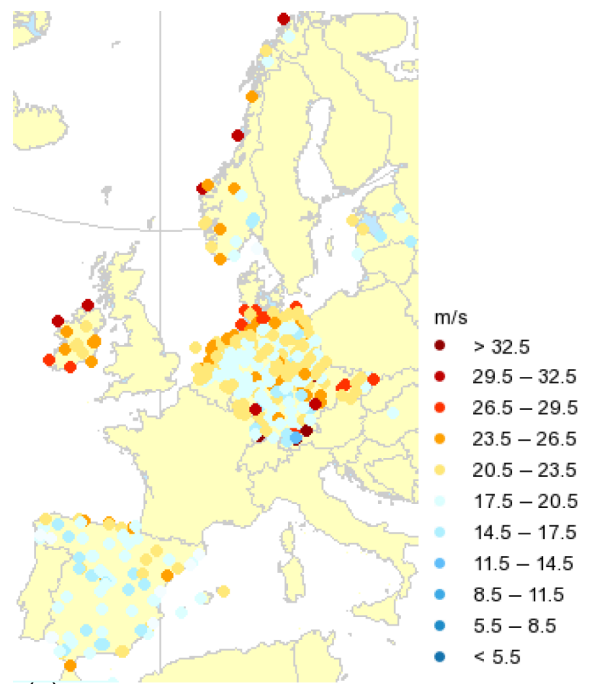

(a)

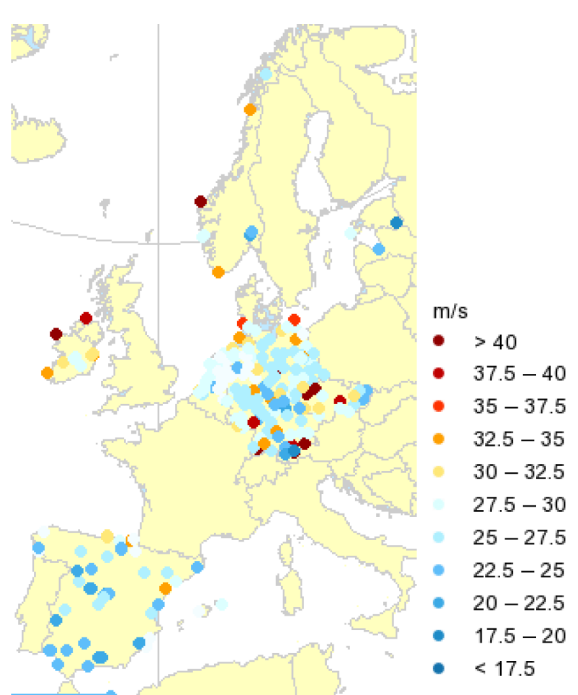

(b)

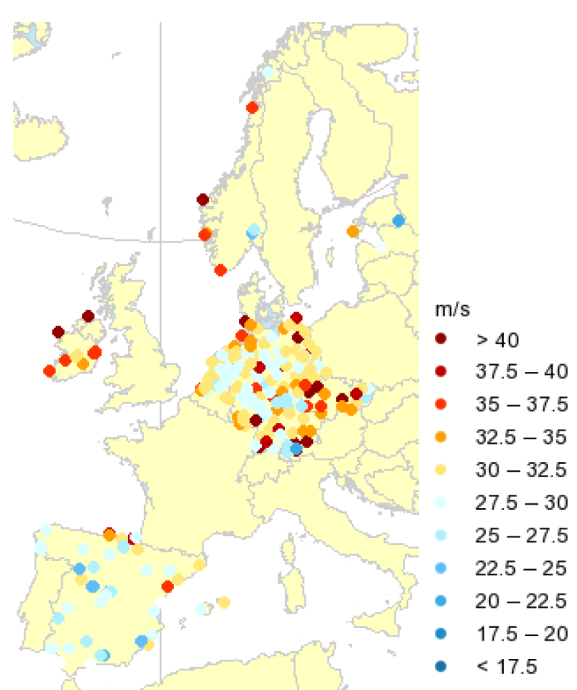

(c)

Fig. 5. (a) Maximum wind gust $\left(\mathrm{m} \mathrm{s}^{-1}\right.$ ) based on 1991-2010 period which occurs 10 times per year. (b) Two year return values of annual maximum wind gust $\left(\mathrm{m} \mathrm{s}^{-1}\right.$ ) based on 1991-2010 period. (c) Five year return values of annual maximum wind gust (m s${ }^{-1}$ ) based on 1991-2010 period. Maps of (b) and (c) are available at: http://www.ecad.eu/utils/mapserver/returnvalues.php.

Table 4. Median of the return values of the annual maximum wind gusts for 1991-2010 $\left(\mathrm{m} \mathrm{s}^{-1}\right)$. The number of stations on which the median is based is shown between brackets, and the current thresholds $\left(\mathrm{m} \mathrm{s}^{-1}\right)$ are shown in italic. Latvia is excluded from this table; the only station for which the Gumbel fit passed the Anderson-Darling test (Riga) is too far from the coast to be regarded as a coastal station and falls in the intermediate category.

10 times/year return values and current thresholds for yellow warning

\begin{tabular}{|c|c|c|c|c|c|c|c|}
\hline & The Netherlands & Germany & Ireland & Norway & Spain & Czech Republic & Estonia \\
\hline coastal & $24.1(10) 20.8$ & 25.7 (4) 18.1 & $31.4(3) 19.4$ & $25.7(5)$ & $20.0(29) 19.4$ & - & 23.0 (1) 15.3 \\
\hline inland & 19.5 (14) 20.8 & $19.9(92) 18.1$ & $22.6(5) 19.4$ & $17.3(3)$ & $18.6(28) 19.4$ & $22.2(12) 19.4$ & 16.0 (1) 15.3 \\
\hline mountain & - & $25.2(16) 18.1$ & - & $23.8(1)$ & $18.8(20) 19.4$ & $25.4(6) 19.4$ & - \\
\hline \multicolumn{8}{|c|}{$2 \mathrm{yr}$ return values and current thresholds for orange warning } \\
\hline coastal & 29.4 (4) 32.7 & 32.7 (4) 29.2 & 39.5 (3) 30.6 & $32.4(4)$ & $26.1(20) 25$ & - & 29.3 (1) 25 \\
\hline inland & 25.9 (13) 20.8 & 26.5 (91) 29.2 & 28.9 (4) 30.6 & $22.7(3)$ & 24.4 (18) 25 & 28.8 (9) 25 & 19.9 (1) 25 \\
\hline mountain & - & 33.5 (16) 29.2 & - & - & $25.1(6) 25$ & 30.5 (4) 25 & - \\
\hline \multicolumn{8}{|c|}{$5 \mathrm{yr}$ return values and current thresholds for red warning } \\
\hline coastal & $32.1(4)$ & 35.7 (4) 38.9 & 44.1 (3) 36.1 & 35.7 (4) 43 & 29.6 (20) 36.1 & - & 33.6 (1) 33.3 \\
\hline inland & $28.8(13)$ & 30.2 (91) 38.9 & 32.3 (4) 36.1 & 25.4 (3) 43 & 27.2 (18) 36.1 & 33.6 (9) 30.6 & 22.3 (1) 33.3 \\
\hline mountain & - & 37.5 (16) 38.9 & - & - & 27.7 (6) 36.1 & 34.8 (4) 30.6 & - \\
\hline \multicolumn{8}{|c|}{$10 \mathrm{yr}$ return values } \\
\hline coastal & $33.9(4)$ & $37.8(4)$ & $46.7(3)$ & 37.9 (4) & $31.7(20)$ & - & $36.4(1)$ \\
\hline inland & 30.9 (13) & $32.6(91)$ & $34.6(4)$ & $27.2(3)$ & $29.2(18)$ & 36.7 (9) & $23.9(1)$ \\
\hline mountain & - & $40.3(16)$ & - & - & $29.3(6)$ & $37.6(4)$ & - \\
\hline \multicolumn{8}{|c|}{$50 \mathrm{yr}$ return values } \\
\hline coastal & $37.9(4)$ & $42.2(4)$ & $52.5(3)$ & $42.8(4)$ & $36.4(20)$ & - & $42.7(1)$ \\
\hline inland & $35.4(13)$ & $37.8(91)$ & $39.5(4)$ & $31.2(3)$ & $33.3(18)$ & $42.9(9)$ & $27.4(1)$ \\
\hline mountain & - & $46.5(16)$ & - & - & $33.0(6)$ & 43.7 (4) & - \\
\hline
\end{tabular}




\subsection{Comparing yellow warning thresholds}

For the inland areas, the NMS thresholds currently used for the yellow warnings are close to the values suggested in this study. For the coastal areas and mountain areas however, the suggested values are higher than those currently in use. Table 4 shows that for inland areas the differences between the suggested threshold values and the values currently in use vary between $-1.3 \mathrm{~m} \mathrm{~s}^{-1}$ (The Netherlands) and $3.2 \mathrm{~m} \mathrm{~s}^{-1}$ (Ireland). For coastal areas this difference varies between $0.6 \mathrm{~m} \mathrm{~s}^{-1}$ (Spain) and $12.0 \mathrm{~m} \mathrm{~s}^{-1}$ (Ireland), for mountain areas between $-0.6 \mathrm{~m} \mathrm{~s}^{-1}$ (Spain) and $7.1 \mathrm{~m} \mathrm{~s}^{-1}$ (Germany).

\subsection{Comparing orange warning thresholds}

The alternative orange warning thresholds based on the median of the $2 \mathrm{yr}$ return values of the annual maximum wind gusts are also summarized in Table 4 . The alternative thresholds do not differ significantly from the NMS thresholds for the inland area. Germany and Estonia have the largest differences, with suggested thresholds respectively $2.8 \mathrm{~m} \mathrm{~s}^{-1}$ higher and $5.1 \mathrm{~m} \mathrm{~s}^{-1}$ lower than the NMS thresholds. For the coastal region, the differences are larger. The suggested thresholds for The Netherlands are $3.3 \mathrm{~m} \mathrm{~s}^{-1}$ lower than those currently in use and for Ireland they are $8.9 \mathrm{~m} \mathrm{~s}^{-1}$ higher. The suggested thresholds for mountain areas are 4.3 (Germany) and $5.5 \mathrm{~m} \mathrm{~s}^{-1}$ (Czech Republic) higher than the NMS thresholds.

\subsection{Comparing red warning thresholds}

Table 4 also compares the red warning thresholds in use and the $5 \mathrm{yr}$ return values of the annual maximum wind gusts. For code red, the largest differences between the $5 \mathrm{yr}$ return values and the NMS thresholds are found. For the coastal areas, the $5 \mathrm{yr}$ return levels are approx. $7 \mathrm{~m} \mathrm{~s}^{-1}$ lower than the NMS levels currently in use (The Netherlands, Norway, Spain) or $6 \mathrm{~m} \mathrm{~s}^{-1}$ higher (Ireland). For the inland area, all countries have lower $5 \mathrm{yr}$ return values than NMS thresholds (up to 10-17 m s${ }^{-1}$ ), except the Czech Republic which has a $5 \mathrm{yr}$ return value which is $3 \mathrm{~m} \mathrm{~s}^{-1}$ higher. For the mountain regions, Spain has a $5 \mathrm{yr}$ return level which is $8.6 \mathrm{~m} \mathrm{~s}^{-1}$ lower than the NMS threshold while the differences for Germany and the Czech Republic are very small.

\section{Discussion}

\subsection{Availability and uniformity of data}

So far, only a third of the 30 Meteoalarm countries provide daily wind gust data to ECA\&D. Although most of the countries along the west coast of Europe are represented, the scarcity of data over much of Europe remains a problem for a pan-European assessment of wind gust warnings.
The lack of uniformity in how each country calculates daily values is another problem which interferes with such efforts. These differences in aggregation are described in Table 2 and more details are provided on the ECA\&D website.

The quality control of daily maximum wind gusts and daily mean wind speeds by using simple limit checks and a check on their ratio may be improved by using the more sophisticated approach of Graybeal (2006), where a quantity related to the ratio of daily maximum wind gust and daily mean wind speeds is fitted to a distribution in logspace. Measurements sufficiently outside the distribution were flagged as suspect. However, the lack of uniformity in aggregating daily maximum wind gusts and daily mean wind speed might make Graybeal (2006)'s approach less applicable.

\subsection{Homogeneity of data}

Homogeneity tests are required for reliable calculations of climatic trends. One needs to exclude "breaks" and artificial trends in order to make sure that the trend one discovers in the data is indeed due to climatic change and not to relocations of stations, changes in the station surroundings or changes in measuring equipment or methods. Inhomogeneities in data also interfere with a reliable estimate of return values. Several homogeneity tests for wind data were tried, including the Petrovic Redistribution index (RDI, Petrovic, 2004) for the daily wind direction and the standard ECA\&D homogeneity tests (Wijngaard et al., 2003) for the annual average of the wind gust factor. The latter is the aggregate of daily maximum wind gust divided by the daily average wind speed, (provided the latter is non-zero). However, these tests were not implemented for this study because of the experimental character of the RDI and the fact that the completeness requirements were not met for many years in the calculation of the wind gust factor.

It would be interesting to investigate homogeneity tests based on comparing the measurement series to a reference series such as the geostrophic wind (Wan et al., 2010).

Metadata are essential for verifying the homogeneity of climate time series and are especially important for wind measurements because gradual changes in the surface roughness of the surroundings or station relocations can introduce non-climatic trends in the data. Metadata are therefore included in the ECA\&D dataset where available. In this study metadata have also proved useful in the process of eliminating outliers (see Appendix B).

\subsection{Seasonal dependency of return values}

The Netherlands have recently increased the orange warning winter threshold for coastal areas from 27.7 to $33.3 \mathrm{~m} \mathrm{~s}^{-1}$ based on an earlier analysis of return values (Wever, 2009). The analysis in the current paper also shows that for The Netherlands the once in $2 \mathrm{yr}$ gusts are on average $5-7 \mathrm{~m} \mathrm{~s}^{-1}$ 


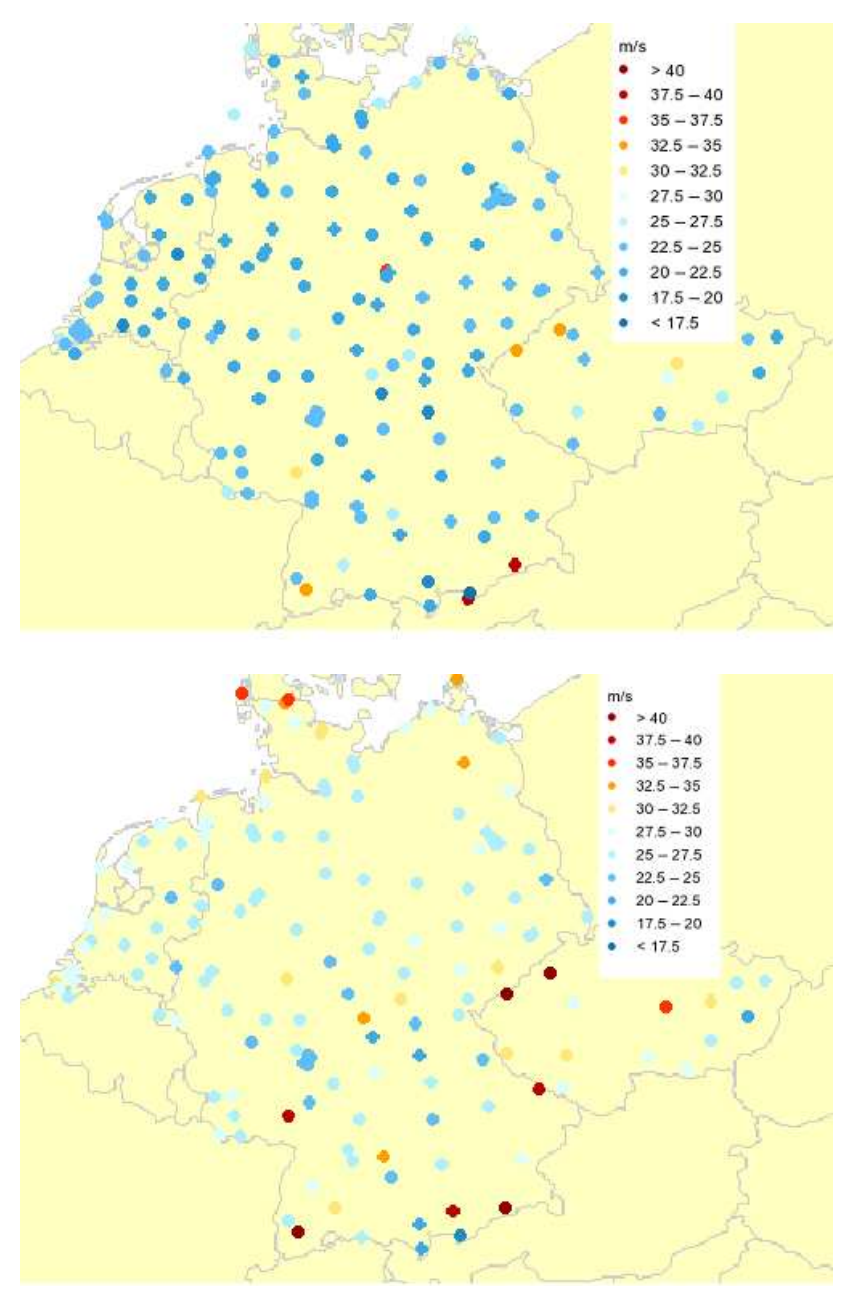

Fig. 6. Two year return values of seasonal maximum wind gust $\left(\mathrm{m} \mathrm{s}^{-1}\right)$ based on 1991-2010 period for the summer half year (upper panel) and the winter half year (lower panel). Maps are available at http://www.ecad.eu/utils/mapserver/returnvalues.php.

higher in the winter half year than in the summer half year (Fig. 6), but not only for coastal areas. It would be worthwhile investigating if a similar seasonal difference can be found for other countries and whether the difference can be explained by convection being the main cause of severe gustiness in the summer half year and synoptic scale weather systems in the winter half year.

\subsection{Additional considerations when reviewing severe weather alarm thresholds}

In this study the median of the return values of a given area is investigated as a uniform guideline for reviewing warning thresholds, but there are alternative methods worth investigating. Using the median implies that on average half of the stations in the warning area experience a wind gust exceeding the threshold during the return period, whereas a warning might be necessary if a lower or higher fraction of the stations is affected. Whether or not a warning is issued also depends on how densely populated the affected area is and whether or not almost everyone is safe indoors, e.g. at night. Thus setting warning thresholds remains a partly subjective task. The size of the area affected is a good first approximation of the number of lives at risk and of how large the economic damage might be. For example, in The Netherlands the orange and red warnings are only issued if a large enough area is likely to be affected. This minimum area affected (MAA) is $50 \mathrm{~km}^{2}$, which is a bit less than $10 \%$ of the total land area. For these warnings the median return value is less appropriate than the $10 \%$ quantile, which would mean that one tenth of the Dutch stations experience a daily maximum wind gust exceeding the threshold. Obviously, the MAA's will vary per country and in some cases per region.

\section{Conclusions}

Meteoalarm is the EUMETNET initiative for a pan-European severe weather warning system. Although Meteoalarm provides guidelines for warning thresholds for the different kinds of severe weather, the NMSs of the member countries are responsible for choosing the thresholds, often in an elaborate process involving various stakeholders, government officials and meteorologists. The main drawback of the exclusive national focus in this process is that the issuing frequency need not be similar to neighbouring countries. As a result of determining warning thresholds at a national level, questionable differences in the frequency and level of warnings between neighbouring countries are observed.

In order to assist the Meteoalarm community of NMSs with the ongoing optimization of their warning systems for extreme wind gusts, a methodology is proposed and demonstrated that can be used to help alleviate some of the differences between neighbouring countries and regions. This methodology is based on pan-European uniform return periods. In this study we chose to use return periods of 10 times a year for code yellow warnings, once in $2 \mathrm{yr}$ for code orange and once in $5 \mathrm{yr}$ for code red which roughly correspond to the Meteoalarm guideline for a median sized country. The return values that correspond to these uniform return periods are different for each individual country. They are a measure of how extreme an event is compared to the local climate and are a powerful means of predicting the possible danger of an event and its impact on society.

The results of this study indicate that warnings for hazardous wind gusts should be regionalised for coastal, inland and mountainous areas. The median return values and the NMS thresholds concur reasonably well for the inland areas but less well for coastal and mountainous areas. This makes sense because NMSs generally do not regionalise their warning thresholds and base them on past experience of damage in densely populated, and therefore non-mountainous, areas. This supports the premise that the return periods chosen 
in this study are an appropriate basis for new Meteoalarm guidelines.

The fact that the median return values differ from the NMS thresholds in coastal and mountainous areas suggests that it would be beneficial to introduce separate thresholds for these areas.

In ECA\&D there are other measurements of the weather, such as daily maximum and minimum temperature, snow depth and daily precipitation amount, that can be used to improve and harmonise the Meteoalarm guidelines for hazardous weather parameters other than the extreme wind gusts considered here. These improved guidelines will aid NMSs when they choose to review their warning thresholds.

In closing, it must be noted that climate change will have an impact upon the frequency of occurrence of daily climatic extremes and severe weather events (Moberg et al., 2006; Alexander et al., 2006). Statistics derived from historical time series may no longer be representative for future climate. The climate change may impact on the regionalization of severe weather thresholds as well. Recently, McVicar et al. (2010) observed a divergence in the speed of decline in near-surface wind speed measurements for high and low elevation stations, which may fuel the need to regionalise wind gust warnings.

This perspective on gradual changes in threshold values for severe weather warnings could not be taken into account in the present study because of limitations in data availability which prevents implementation of homogeneity tests. Nevertheless, the methodology of relating warning thresholds to return values for specified return periods is perfectly capable of including the climate change perspective by shifting the time window for the data used to more recent years, or including projected changes in the statistical analysis.

\section{Appendix A}

\section{Quality control}

The data in ECA\&D are checked for coding errors, like nonexistent dates, directions greater than 360 degrees, daily wind speeds that exceed the daily maximum wind gust and negative wind speeds, wind gusts and directions. Erroneous outliers are also flagged as suspect using fixed thresholds for daily maximum wind gust and average wind speed. Furthermore, the wind data are considered suspect if, for a number of successive non-calm days, the values remain the same.

The outlier criteria for wind gusts are based on extremes found in the literature. McClatchey (1996) reports on the highest official Scottish gust, which was $77 \mathrm{~m} \mathrm{~s}^{-1}$ at Cairngorm summit on 20 March 1986. Lamb and Frydendahl (1991) report on two higher but unofficial wind gusts of 79 and $84 \mathrm{~m} \mathrm{~s}^{-1}$ from the islands Unst and Jan Mayen, respectively, far north of the Scottish mainland. Ceppi et al. (2008) show wind gusts of $74 \mathrm{~m} \mathrm{~s}^{-1}$ from two mountains (above
$2400 \mathrm{~m}$ ) in Switzerland. The upper limit which WMO advises for wind gust measurements is $75 \mathrm{~m} \mathrm{~s}^{-1}$ (World Meteorological Organization, 1996), but bearing in mind the Cairngorm record, the upper limit for daily maximum wind gusts was set a little higher at $76 \mathrm{~m} \mathrm{~s}^{-1}$.

In order to base the outlier limit for average wind speed $(f g)$ on that for the maximum wind gust $(f x), f g / f x$ was calculated for the five stations with the highest wind speeds in winter based on their 1971-2000 climatology. They were all coastal stations, exposed to the prevailing strongest winds on the seaward side. These stations have a low surface roughness in the direction of the strongest winds so the ratio of $f g$ to $f x$ should provide an upper limit. The five stations selected are Bjørnøya, Fuholmen Fyr and Slettnes Fyr from Norway, Helgoland (Germany) and Texelhors (the Netherlands). For these stations, daily values of $f g / f x$ are calculated for the days with $f g \geq 13.9 \mathrm{~m} \mathrm{~s}^{-1}$ (7 Beaufort or higher). This resulted in a sample of (in total) 2622 days in the 1971-2000 period. The median ratio varied between $0.59 \pm 0.09$ for Slettnes Fyr to $0.63 \pm 0.07$ for Texelhors. Based on this analysis, we set the ratio to 0.6 . Sixty percent of the $76 \mathrm{~m} \mathrm{~s}^{-1}$ wind gust outlier criterion was therefore used for the daily average wind speed upper limit of $46 \mathrm{~m} \mathrm{~s}^{-1}$.

In the repetitive test, data are flagged as suspect when there are more than 4 successive days with the same wind gust or more than 5 successive days with the same wind speed or direction, excluding calm periods. Here the definition of calm used depends upon the element being considered: for direction $(d d), d d=0$ was used (which is the WMO meteorological code for calm), for gust, $f x<4 \mathrm{~m} \mathrm{~s}^{-1}$ and for speed, $f g<2 \mathrm{~m} \mathrm{~s}^{-1}$ (Tsai et al., 2004).

The results of the tests (dated January 2012) are summarized in Tables A1-A3. Shown are, respectively, the total number of daily data per country for wind gust, speed and direction, the percentage of data that are missing and the percentage of non-missing data rejected by the tests. The repetitive test rejects an unusually high number of Norwegian and Spanish wind directions. This could be due to reporting wind direction in compass points, e.g. N, NE, E, etc., which was common practice in some countries before the introduction of automatic weather stations: the Norwegian data certainly show large peaks in the frequency distribution for these directions. A longer period of successive days should be used in the test for (older parts of) data series showing such peaks.

An exceptionally large amount of the Norwegian wind gust data is flagged as suspect for exceeding the limit of $76 \mathrm{~m} \mathrm{~s}^{-1}$. Twelve stations not used in this study were responsible for all the unacceptably high gusts. For more than $95 \%$ of these days no other station in Norway could be found with gusts above $46 \mathrm{~m} \mathrm{~s}^{-1}$. This suggests that the gusts above $76 \mathrm{~m} \mathrm{~s}^{-1}$ are indeed erroneous and indicates that the quality control is working correctly. 
Table A1. Wind gust completeness and quality control. Data sampled in January 2012.

\begin{tabular}{lrrrrrr}
\hline Country & Total & Missing $(\%)$ & Suspect $(\%)$ & Repetitive $(\%)$ & Bounds $(\%)$ & $f x<f g(\%)$ \\
\hline Germany & 2664382 & 8.53 & 0.04 & 0.03 & 0.00 & 0.01 \\
The Netherlands & 522725 & 3.43 & 0.08 & 0.07 & 0.00 & 0.00 \\
Ireland & 265666 & 2.66 & 0.02 & 0.02 & 0.00 & 0.00 \\
Norway & 455887 & 3.17 & 0.04 & 0.02 & 0.02 & 0.00 \\
Luxembourg & 4658 & 3.24 & 0.00 & 0.00 & 0.00 & 0.00 \\
Hungary & 14244 & 0.00 & 0.00 & 0.00 & 0.00 & 0.00 \\
Spain & 1536935 & 14.03 & 0.05 & 0.05 & 0.00 & 0.00 \\
Czech Republic & 454357 & 13.82 & 1.27 & 0.07 & 0.00 & 1.20 \\
Latvia & 94230 & 0.00 & 0.00 & 0.00 & 0.00 & 0.00 \\
Estonia & 33602 & 1.46 & 0.32 & 0.32 & 0.00 & 0.00 \\
\hline
\end{tabular}

Table A2. Wind speed completeness and quality control. Data sampled in January 2012.

\begin{tabular}{lrrrrrr}
\hline Country & Total & Missing $(\%)$ & Suspect $(\%)$ & Repetitive $(\%)$ & Bounds $(\%)$ & $f x<f g(\%)$ \\
\hline Germany & 3099756 & 6.00 & 0.01 & 0.00 & 0.00 & 0.01 \\
The Netherlandsl & 728593 & 1.49 & 0.02 & 0.02 & 0.00 & 0.00 \\
Ireland & 254126 & 3.32 & 0.01 & 0.00 & 0.00 & 0.01 \\
Norway & 1528845 & 3.90 & 0.01 & 0.01 & 0.00 & 0.00 \\
Slovakia & 193923 & 0.05 & 0.00 & 0.00 & 0.00 & 0.00 \\
Slovenia & 517782 & 3.70 & 0.02 & 0.02 & 0.00 & 0.00 \\
Spain & 1750134 & 7.45 & 2.42 & 0.00 & 0.00 & 2.42 \\
Czech Republic & 756926 & 1.36 & 0.90 & 0.21 & 0.00 & 0.69 \\
Latvia & 94230 & 0.00 & 0.00 & 0.00 & 0.00 & 0.00 \\
Estonia & 33602 & 1.84 & 0.00 & 0.00 & 0.00 & 0.00 \\
\hline
\end{tabular}

\section{Appendix B}

\section{Metadata and outliers}

In the calculation of the data shown in Fig. 3, it was observed that Avila (Spain) and Garmisch Partenkirche (Germany) had much lower 2 yr return values than other mountain stations with similar elevations. The $2 \mathrm{yr}$ return values were as low as 22.3 and $17.8 \mathrm{~m} \mathrm{~s}^{-1}$. These values have been left out of the analysis since these measurement sites are situated in a built-on area like a town and therefore not representative for a typical mountain station. There are other stations with elevations $\geq 700 \mathrm{~m}$ situated in towns, but the Gumbel fit of these stations did not pass the Anderson-Darling test, which meant that they were not used in this analysis.

Figure 3 shows two stations, near $150 \mathrm{~km}$ and $225 \mathrm{~km}$, which show return values much lower than stations with a comparable distance to the coast line. These stations are Voru (Estonia) and Zamora (Spain), respectively. The first of these stations is on a field at the edge of town surrounded by semicircle of buildings and the latter one is in a built-on area (albeit with train tracks to the north and east) which may explain the low return values.

In the calculations leading up to Fig. 3, a number of stations produce much higher return values than comparable stations. Station Berlin-Alexanderplatz measures $6-7 \mathrm{~m} \mathrm{~s}^{-1}$ higher return values than the other 5 Berlin stations in this study. A Google-maps search made us suspect that the anemometer is on the tall television mast. The wind mast at Weinbiet is not only very exposed on top of a panorama tower on a forested hill, but may also measure the wind at a height more than $10 \mathrm{~m}$ above the ground. The return values measured at Weinbiet are unrealistically higher than those from the other inland stations we have analysed $\left(39.6 \mathrm{~m} \mathrm{~s}^{-1}\right.$ once in $2 \mathrm{yr}$ and $43.6 \mathrm{~m} \mathrm{~s}^{-1}$ once in $5 \mathrm{yr}$ ). Data from BerlinAlexanderplatz and Weinbiet are removed from Fig. 3.

Other outliers are associated with the stations Buckeburg and Neubrandenburg in Germany and Luka, Kocelovice and Pribyslav in the Czech Republic. Although the difference in elevation between Buckeburg and nearby Hannover (both airports) is about $120 \mathrm{~m}$, this cannot be enough reason to explain why return values at Buckeburg are about $7 \mathrm{~m} \mathrm{~s}^{-1}$ higher. There are no obvious stations to compare Neubrandenburg to and although we can make out that Neubrandenburg seems to be on the slope of a hill, the available metadata does not give a definite clue as to why return values are so high. Stations Luka, Kocelovice and Pribyslav are not extremely elevated above the surrounding landscape, but are on exposed hills in remote areas with no buildings and trees which may explain why the measured return values are outliers. Data from these stations are removed from Fig. 3 as well. 
Table A3. Wind direction completeness and quality control. Data sampled in January 2012.

\begin{tabular}{lrrrrrr}
\hline Country & Total & Missing (\%) & Suspect (\%) & Repetitive (\%) & Bounds (\%) & \\
\hline The Netherlands & 728516 & 1.76 & 0.00 & 0.00 & 0.00 & 0.00 \\
Ireland & 268117 & 1.51 & 0.01 & 0.01 & 0.00 & 0.00 \\
Norway & 1618572 & 3.96 & 0.49 & 0.49 & 0.00 & 0.00 \\
Luxembourg & 4658 & 3.24 & 0.67 & 0.00 & 0.67 & 0.00 \\
Spain & 2259254 & 9.99 & 1.85 & 1.85 & 0.00 & 0.00 \\
Latvia & 94230 & 0.00 & 0.00 & 0.00 & 0.00 & 0.00 \\
\hline
\end{tabular}

Figure 4 shows data of a few "mountain" stations that give 2 yr return values that are much lower than other mountain stations, and even lower than some inland stations. Spanish station Burgos-Villafria at an elevation of $890 \mathrm{~m}$, gives a $2 \mathrm{yr}$ return value of only $26.9 \mathrm{~m} \mathrm{~s}^{-1}$. The station is in a built-on area near trees which may (partly) explain the low $2 \mathrm{yr}$ return value. A mountain station with an even lower $2 \mathrm{yr}$ return value $\left(17 \mathrm{~m} \mathrm{~s}^{-1}\right)$ is Garmisch Partenkirchen in Germany. This station is not only in a town, but also in a valley surrounded by high mountains and therefore very sheltered. Also at rural station Oberstdorf in Germany, which is in a valley at $806 \mathrm{~m}$ surrounded by high peaks, the $2 \mathrm{yr}$ return value is low $\left(22 \mathrm{~m} \mathrm{~s}^{-1}\right)$. Both German stations Kleiner Feldberg/Taunus at $826 \mathrm{~m}$ and Neuhaus am Rennweg at $845 \mathrm{~m}$ are surrounded by forest (although the actual hill top itself is bare at Feldberg/Taunus, the forest is close) which might explain the relatively low $2 \mathrm{yr}$ return values that are measured there (respectively 26 and $27.6 \mathrm{~m} \mathrm{~s}^{-1}$ ). For Spanish station Leon Virgen del Camino (airport at an elevation of $916 \mathrm{~m}$ ) we could not find a plausible explanation why the $2 \mathrm{yr}$ return value is low $\left(26.6 \mathrm{~m} \mathrm{~s}^{-1}\right)$. The same goes for Czech mountain station Churanov which gives a $2 \mathrm{yr}$ return value of $29.4 \mathrm{~m} \mathrm{~s}^{-1}$ at an elevation of $1117.8 \mathrm{~m}$ : the station is an observatory on top of a hill and the only reason why the return value might be relatively low, is that there are pine trees quite close to the observatory. Data for these stations is not removed from Fig. 4.

Acknowledgements. Thanks to the European Climate Assessment and Dataset participants for providing the wind data and the Meteoalarm community, especially Frank Kroonenberg, for their active cooperation. Further thanks go to the Weather Department of the Royal Netherlands Meteorological Institute KNMI for freeing the lead authors from their operational work to do this research and the colleagues from the Climate Services Department of the KNMI for their help and support. Data and figures are available via http://www.ecad.eu.

Edited by: U. Ulbrich

Reviewed by: three anonymous referees

\section{References}

Alexander, L., Zhang, X., Peterson, T., Caesar, J., Gleason, B., Klein Tank, A., Haylock, M., Collins, D., Trewin, B., Rahimzadeh, F., Tagipour, A., Rupa Kumar, K., Revadekar, J., Griffiths, G., Vincent, L., Stephenson, D., Burn, J., Aguilar, E., Brunet, M., Taylor, M., New, M., Zhai, P., Rusticucci, M., and Vazquez-Aguirre J.: Global observed changes in daily climate extremes of temperature and precipitation, J. Geophys. Res.Atmos., 111, D05109, doi:10.1029/2005JD006290, 2006.

Barthelmie, R. J. and Pryor, S. C.: Challenges in predicting power output from offshore wind farms, J. Energy Eng., 132, 91-103, 2004.

Ceppi, P., Della-Marta, P., and Appenzeller, C.: Extreme value analysis of wind speed observations over Switzerland, Tech. Rep. report number 219, MeteoSwiss, 2008.

Graybeal, D. Y.: Relationships among daily mean and maximum wind speeds with application to data quality assurance, Int. J. Climatol., 26, 29-43, doi:10.1002/joc.1237, 2006.

Hogg, W. and Swail, V.: Effects of distributions and fitting techniques on extreme value analysis of modelled wave heights, in: 7th Int. Workshop on Wave Hind-casting and Forecasting, Banff, Canada, 140-150, 2002.

Klein Tank, A. M. G., Wijngaard, J. B., Können, G. P., Böhm, R., Demarée, G., Gocheva, A., Milate, M., Pashiardis, S., Hejkrlik, L., Kern-Hansen, C., Heino, R., Bessemoulin, P., MüllerWestermeier, G., Tzanakou, M., Szalai, S., Pálsdóttir, T., Fitzgerald, D., Rubin, S., Capaldo, M., Maugeri, M., Leitass, A., Bukantis, A., Aberfeld, R., van Engelen, A. F. V., Forland, E., Mietus, M., Coelho, F., Mares, C., Razuvaev, V., Nieplova, E., Cegnar, T., Antonio López, J., Dahlström, B., Moberg, A., Kirchhofer, W., Ceylan, A., Pachaliuk, O., Alexander, L., and Petrovic, P.: Daily dataset of 20th-century surface air temperature and precipitation series for the European Climate Assessment, Int. J. Climatol., 22, 1441-1453, data and metadata available at: http://eca.knmi.nl, 2002.

Klok, E. J. and Klein Tank, A. M. G.: Updated and extended European dataset of daily climate observations, Int. J. Climatol., 29, 1182-1191, doi:10.1002/joc.1779, 2008.

Lamb, H. and Frydendahl, K.: Historic storms of the North Sea, British Isles and Northwest Europe, Cambridge University Press, Cambridge, New York, 1991.

Liu, S. and Liang, X.: Observed Diurnal Climatology of Planetary Boundary Layer Height, J. Climate, 23, 5790-5809, doi:10.1175/2010JCLI3552.1, 2010.

McClatchey, J.: Spatial and Attitudinal Gradients of Climate in the Cairngorms: Observations from Climatological and Automatic 
Weather Stations, J. Botan. Soc. Scotland, 48, 31-49, 1996.

McVicar, T. R., Van Niel, T. G., Roderick, M. L., Li, L. T., Mo, X. G., Zimmermann, N. E., and Schmatz, D. R.: Observational evidence from two mountainous regions that near-surface wind speeds are declining more rapidly at higher elevations than lower elevations: 1960:2006, Geophys. Res. Lett., 37, L06402, doi:10.1029/2009GL042255, 2010.

Moberg, A., Jones, P. D., Lister, D., Walther, A., Brunet, M., Jacobeit, J., Alexander, L. V., Della-Marta, P. M., Luterbacher, J., Yiou, P., Chen, P., Klein Tank, A. M. G., Saladié, O., Sigró, J., Aguilar, E., Alexandersson, H., Almarza, C., Auer, I., Barriendos, M., Begert, M., Bergström, H., Böhm, R., Butler, C. J., Ceasar, J., Drebs, M., Founda, D., Gerstengrabe, F.-W., Micela, G., Maugeri, M., Österle, H., Pandzic, K., Petrakis, M., Srnec, L., Tolasz, R., Tuomenvirta, H., Werner, P. C., Linderholm, H., Philipp, A., Wanner, H., and Xoplaki, E.: Indices for daily temperature and precipitation extremes in Europe analyzed for the period 1901-2000, J. Geophys. Res.-Atmos., 111, D22106, doi:10.1029/2006JD007103, 2006.

Munich Re: Great natural disasters since 1950, available at: http:// www.munichre.com/en/reinsurance/business/non-life/georisks/ natcatservice/long-term_statistics_since_1950/default.aspx (last access: 4 October 2010), 2009.

Perrin, O., Rootzen, H., and Taesler, R.: A discussion of statistical methods used to estimate extreme wind speeds, Theor. Appl. Climatol., 85, 203-215, 2006.

Petrovic, P.: Detecting of inhomogeneities in time series using Real Precision Method, in: Fourth seminar for homogenization and quality control in climatological databases, WCDMP-No. 56, WMO-TD No. 1236, WMO, Geneva, Ch., 2004.
Stephens, M.: Tests based on EDF statistics, in: Goodness-of-fit techniques, edited by: D’Agostino, R. and Stephens, M., Marcel Dekker, New York, USA, 97-193, 1986.

Tsai, C.-J., Aggarwal, S., Chang, C.-T., and Hung, I.-F.: Concentration profiles of acidic and basic air pollutants around an industrial part of Taiwan, Water Air Soil Pollut., 151, 287-304, 2004.

van den Besselaar, E. J. M., Klein Tank, A. M. G., van der Schrier, G., and Jones, P. D.: Synoptical messages for near-real-time updating of climate data, J. Geophys. Res.-Atmos., 117, DO7101, doi:10.1029/2011JD016687, 2012.

Wan, H., Wang, X. L., and Swail, V. R.: Homogenization and Trend Analysis of Canadian Near-Surface Wind Speeds, J. Climate, 23, 1209-1225, doi:10.1175/2009JCLI3200.1, 2010.

Wever, N.: Windstotenklimatologie Nederland, Tech. Rep. TR-306, KNMI, 2009 (in Dutch).

Wijngaard, J. B., Klein Tank, A. M. G., and Können, G. P.: Homogeneity of 20th century European daily temperature and precipitation series, Int. J. Climatol., 23, 679-692, doi:10.1002/joc.906, 2003.

World Meteorological Organization: Guide to meteorological instruments and methods of observations, Geneva, Ch, wmo reportno. 8, 6th Edn., 1996.

World Meteorological Organization: Manual on the Global Telecommunication System, Geneva, Ch, wmo-no., 386th Edn., 2007. 